\title{
Choroidal Metastasis from Breast Carcinoma
}

\author{
loannis Asproudis ${ }^{a}$ Spiridon Gorezis ${ }^{a}$ Maria Stefaniotou $^{a}$ \\ Dimitrios Peschos ${ }^{b}$ Konstantinos Psilas ${ }^{a}$ \\ Departments of ${ }^{a}$ Ophthalmology and ${ }^{b}$ Forensic Medicine, Faculty of Medicine, University of loannina, \\ loannina, Greece
}

Key Words

Choroidal metastasis · Breast cancer

\begin{abstract}
Objective: To report a case of intraocular metastasis from breast carcinoma. Clinical Presentation and Intervention: A 54-year-old woman diagnosed with multifocal ductal adenocarcinoma, grade III, of the left breast presented with blurred vision of the left eye. Funduscopy under pupil dilation in the left eye revealed a plateaushaped, yellow choroidal focus measuring 4 optic disc diameters and located 3 optic disc diameters below the fovea. The patient was treated with two cycles of docetaxel and capecitabine. One month later the patient's visual acuity improved. Funduscopy confirmed reduction of oedema. Conclusion: This case shows that impaired vision can be an alarming symptom in a breast cancer patient and a description is given of the morphological features that could help in recognizing the smallest detectable breast cancer metastasis.
\end{abstract}

Copyright $(2) 2006$ S. Karger AG, Basel

\section{Introduction}

Ocular metastasis from breast carcinoma was thought to be rare in the past [1], but in recent years several histopathological and clinical reports have shown that the eye is in fact a site of metastasis for several primary tu- mours including breast, lung and prostate cancer [2, 3]. Such metastasis may locate in the orbit, affecting periocular tissue, or may be intraocular, affecting the choroid or retina, usually being solitary, but rarely can combine with other central nervous system metastasis in neighbouring tissue [4].

Intraocular metastasis has been proven to be the most common form of intraocular malignancy $[2,5]$. In up to 80-90\% of female patients with intraocular metastasis, breast cancer is the primary tumour $[3,6]$. Choroidal metastasis represents the smallest detectable lesion of systemic dissemination of breast cancer and is detected at a median of 3 years after diagnosis of the primary tumour [7]. In this report, we present a case of a female patient with choroidal metastasis from breast cancer.

\section{Case Report}

A 54-year-old woman with known history of disseminated multifocal ductal adenocarcinoma, grade III, of the left breast presented with blurred vision in the left eye, 1 year after the initial diagnosis of the cancer. Upon examination it was observed that the visual acuity of the left eye was reduced to $1 / 20 \mathrm{sc}$ compared to $10 / 10 \mathrm{sc}$ of the right eye, using the Snellen optotype. Anterior segment examination did not reveal any findings. Intraocular pressure was within normal limits in both eyes. Ocular motility was normal. Funduscopy under pupil dilation in the right eye did not reveal any pathologic findings but in the left eye there was a plateau-shaped, yellow, choroidal focus. It measured 4 optic disc diameters and was located 3 optic disc diameters below the fovea. The accompanying retinal oedema seemed to extend into the fovea (fig. 1, 2).

\section{KARGER}

Fax +4161306 1234 E-Mail karger@karger.ch www.karger.com
Assistant Prof. Ioannis Asproudis

Department of Ophthalmology

Medical Faculty, University of Ioannina

GR-45110 Ioannina (Greece)

Tel. +30 36945385 626, Fax +30 32651032 266, E-Mail gorezis@hotmail.com 
The patient was admitted to the Oncology Clinic for treatment with two cycles of chemotherapy (docetaxel and capecitabine). One month later the patient's visual acuity was improved to 7-8/10 sc. Fundoscopy confirmed improvement showing oedema reduction and confinement of the choroidal metastatic focus.

\section{Discussion}

Breast cancer accounts for 39-49\% of all uveal metastases [2, 4]. Furthermore the choroid is the most common site of uveal involvement by metastatic disease [7,8]. Probably due to the abundant supply of posterior ciliary arteries to the choroid, especially the posterior choroid [7]. The numerous posterior ciliary vessels allow a greater flow of tumour emboli to the posterior uvea as compared to the fewer anterior ciliary vessels supplying the anterior uvea.

Only a minority of patients with choroidal metastasis are asymptomatic at the time they present to the ophthalmologist. Blurred vision is the most common symptom [6] as in our patient. Other presenting symptoms may include flashes and floaters, even pain. The flashes and floaters typically are related to the presence of subretinal fluid, but the cause of the pain seems to be related to glaucoma or possibly tumour necrosis, inflammation or microscopic scleral involvement [6]. Pain is rarely found with other ocular malignancies.

Recent reports $[6,8]$ have shown that choroidal metastasis from breast cancer is yellow in colour, plateaushaped, with a mean thickness of only $2 \mathrm{~mm}$ in the largest tumour focus [6] as in this case. Choroidal metastasis does not associate with retinal exudates or retinal haemorrhage but usually presents with subretinal fluid.

Ultrasonography has not been able to differentiate various metastatic tumours in the eye [9] and perhaps methods such as fine-needle aspiration biopsy [10] of the choroidal tumour may be more crucial in establishing the diagnosis and determining the primary site using immunohistochemical techniques.

Due to slit-lamp biomicroscopy uveal metastasis is perhaps the smallest detectable breast cancer metastasis in the human body. Lesions as small as $1 \mathrm{~mm}$ can be detected, signalling the need for systemic surveillance. Attention should be targeted especially to the central nervous system since it has been shown that its relative incidence was 3\% in patients with breast cancer before the development of choroidal metastasis while it increased to $46 \%$ after such metastasis [11]. This fact may represent either new metastasis, or more likely, metastasis that was
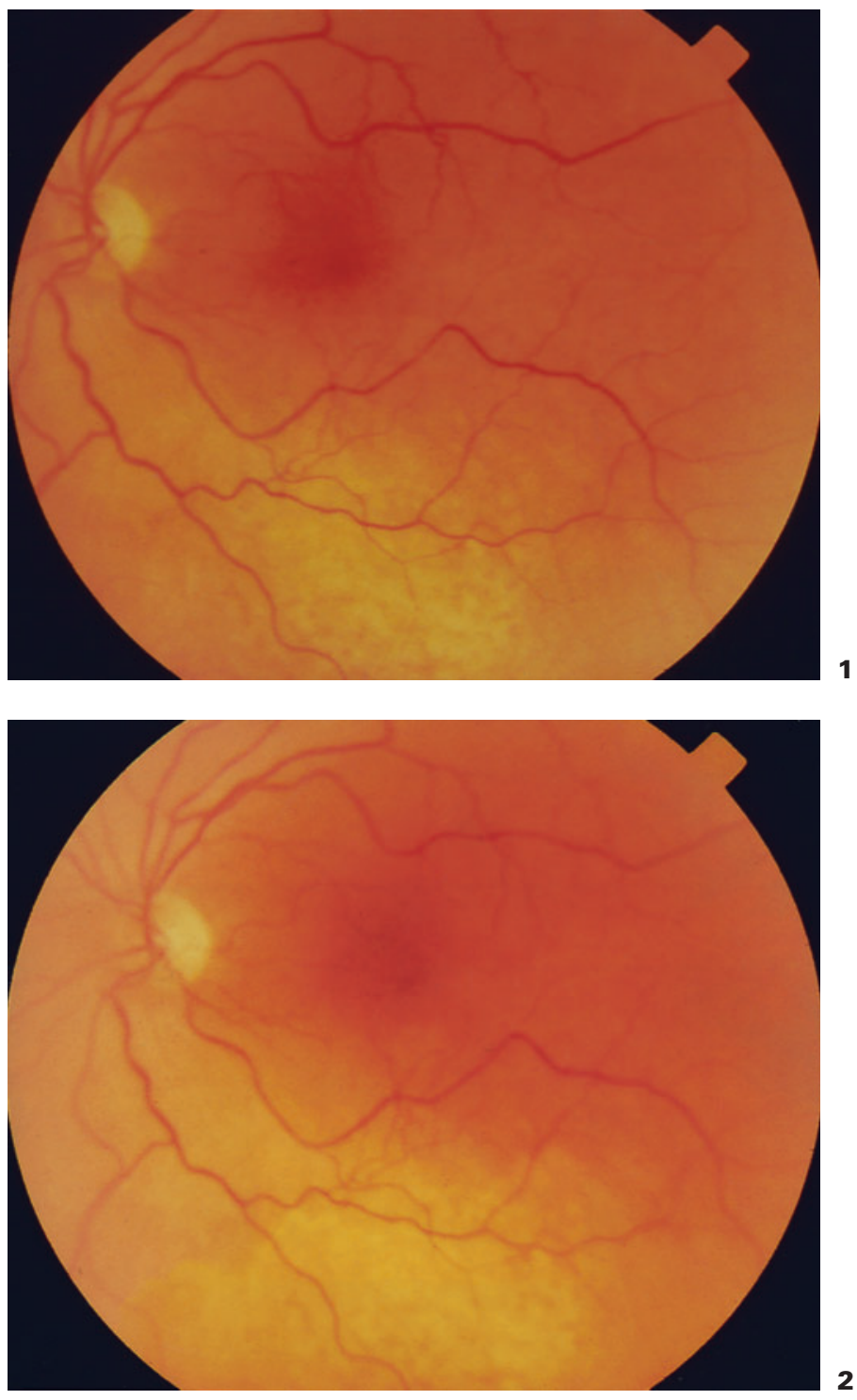

Fig. 1, 2. Choroidal metastasis of breast cancer affecting the fovea.

present but subclinical at the time of ocular diagnosis. The prognosis of patients with metastatic breast cancer and accompanying ocular metastasis is poor [12].

\section{Conclusion}

This case shows that impaired vision can be an alarming symptom in a breast cancer patient and a description is given of the morphological features that could help in recognizing the smallest detectable breast cancer metastasis. 


\section{References}

1 Duke-Elder S: System of Ophthalmology. St Louis, Mosby, 1966, vol 9, p 917.

2 Albert DM, Rubenstein RA, Scheie HG: Tumors metastasis to the eye. Part I: Incidence in 213 adult patients with generalized malignancy. Am J Ophthalmology 1967;63:723-726.

- 3 Freedman MI, Folk JC: Metastatic tumors to the eye and orbit: patient survival and clinical characteristics. Arch Ophthalmol 1987;105: 1215-1219.

- 4 Asproudis I, Gorezis S, Charalabopoulos K, Stefaniotou M, Peschos D, Psilas K: Breast carcinoma metastasis to the orbit and paranasal sinuses: a case report. Exp Oncol 2004;26:246248.
5 Nelson CC, Hertzberg BS, Klintworth GK: A histopathologic study of 716 unselected eyes in patients with cancer at the time of death. Am J Ophthalmol 1983;95:788-793.

-6 Shields CL, Shields JA, Gross NE, Schwartz GP, Lally SE: Survey of 520 eyes with uveal metastases. Ophthalmology 1997;104:12651276.

7 Ferry AP, Font RL: Carcinoma metastatic to the eye and orbit: a clinicopathologic study of 227 cases. Arch Ophthalmol 1974:92:276286.

8 Demirci H, Shields CL, Chao AN, Shields JA: Uveal metastasis from breast cancer in $264 \mathrm{pa}$ tients. Am J Ophthalmol 2003;136:264-271.
-9 De Potter P, Shields JA, Shields CL, Yannuzzi LA, Fisher YE, Rao VM: Unusual MRI findings in metastatic carcinoma to the choroid and optic nerve: a case report. Int Ophthalmol 1992;16:39-44.

10 Shields JA, Shields CL, Ehya H, Eagle RC Jr, De Potter P: Fine-needle aspiration biopsy of suspected intraocular tumors. The $1992 \mathrm{Ur}-$ wick Lecture. Ophthalmology 1993;100:1677_ 1684.

11 Bullock JD, Yanes B: Ophthalmic manifestations of metastatic breast cancer. Ophthalmology 1980;87:961-973.

12 Merrill CF, Kaufman DI, Dimitrov NV: Breast cancer metastatic to the eye is a common entity. Cancer 1991;68:623-627. 